Please do not remove this page

RMIT

UNIVERSITY

\title{
Composition analysis of nickel silicide formed from evaporated and sputtered nickel for microsystem devices
}

Bhaskaran, Madhu; Sriram, Sharath; Du Plessis, Johan; Holland, Anthony

https://researchrepository.rmit.edu.au/esploro/outputs/9921859292601341/filesAndLinks?institution=61RMIT_INST\&index=null

Bhaskaran, M., Sriram, S., Du Plessis, J., \& Holland, A. (2007). Composition analysis of nickel silicide formed from evaporated and sputtered nickel for microsystem devices. Electronics Letters, 43, 479-480.

https://doi.org/10.1049/el:20070203

Published Version: https://doi.org/10.1049/el:20070203

Repository homepage: https://researchrepository.rmit.edu.au

(c) IEE 2007. Personal use of this material is permitted. However, permission to reprint/republish this material for advertising or promotional purposes or for creating new collective works for resale or redistribution to servers or lists, or to reuse any copyrighted component of this work in other works must be obtained from the IEEE.

Downloaded On 2023/04/26 18:54:44 +1000 


\section{Composition analysis of nickel silicide formed from evaporated and sputtered nickel for microsystem devices}

\author{
M. Bhaskaran, S. Sriram, J. du Plessis and A.S. Holland
}

Nickel silicide (NiSi) is highly suitable for microsystem fabrication, exhibiting suitable mechanical properties and good resistance to bulk micromachining etchants. Conditions for the formation of nickel silicide by vacuum annealing thin films of nickel deposited on silicon substrates are investigated. Nickel silicide thin films formed using sputtered and evaporated nickel films were analysed using Auger electron spectroscopy, which has shown that evaporated thin films of nickel tend to form nickel silicide more readily and with less thermal effort.

Introduction: Nickel silicide (NiSi) has good mechanical properties and can be used to form micro-structures such as cantilevers, bridges, and membranes [1]. Formation of micro-structures can involve bulk micromachining of silicon using etchants such as potassium hydroxide $(\mathrm{KOH})$ and tetra-methyl-ammonium hydroxide (TMAH). NiSi has a low etch rate of $0.75 \mathrm{~nm} / \mathrm{min}$ in $25 \% \mathrm{KOH}$ and does not etch in $25 \%$ TMAH [1].

Nickel silicide growth involves the consumption of silicon, when it is formed by thermally reacting deposited nickel on silicon substrates. In this Letter we compare the composition of thin films formed as a result of reacting sputtered nickel and evaporated nickel on silicon. Auger electron spectroscopy depth profiles have been used to study the composition of the thin films formed.

Nickel silicide formation: Thin films $(50 \mathrm{~nm})$ of nickel on (100) n-type silicon substrates were subjected to different vacuum annealing conditions in order to form nickel silicide of the desired monosilicide composition (1:1 nickel and silicon). The nickel thin films were either deposited by DC magnetron sputtering or by electron-beam evaporation. Sputtering was carried out under the conditions listed in Table 1 and evaporation of $50 \mathrm{~nm}$ of nickel was performed from $99.99 \%$ pure nickel sources, after pumping down to a base pressure of $2 \times 10^{-7}$ Torr.

Table 1: DC magnetron sputtering conditions

\begin{tabular}{|c|c|}
\hline Target & Nickel $(99.99 \%)$ \\
\hline Target diameter & $100 \mathrm{~mm}$ \\
\hline DC power & $80 \mathrm{~W}$ \\
\hline Target to substrate distance & $50 \mathrm{~mm}$ \\
\hline Process gas & Argon 5.0 \\
\hline Base pressure & $1.0 \times 10^{-5}$ Torr \\
\hline Sputtering pressure & $1.0 \times 10^{-2}$ Torr \\
\hline Sputtering duration & $60 \mathrm{~s}$ \\
\hline
\end{tabular}

Formation of nickel silicide (NiSi) from silicon takes place through a series of stoichiometric transformations [2]. Nickel thin films on silicon react to form $\mathrm{Ni}_{2} \mathrm{Si}$ at about $250^{\circ} \mathrm{C}$, NiSi at $350^{\circ} \mathrm{C}$, and $\mathrm{NiSi}_{2}$ above $650-700^{\circ} \mathrm{C}$. Patterned nickel samples on (100) n-type silicon were subjected to a one-step or two-step contact anneal process. The following temperatures were among those used to anneal both evaporated and sputtered nickel films $(50 \mathrm{~nm})$ on silicon: (i) $200^{\circ} \mathrm{C}$ for $1 \mathrm{~h}$, followed by $350^{\circ} \mathrm{C}$ for $3 \mathrm{~h}$; (ii) $250^{\circ} \mathrm{C}$ for $1 \mathrm{~h}$, followed by $350^{\circ} \mathrm{C}$ for $3 \mathrm{~h}$; (iii) $250^{\circ} \mathrm{C}$ for $1 \mathrm{~h}$, followed by $400^{\circ} \mathrm{C}$ for $3 \mathrm{~h}$. The samples were placed on a substrate heater in a vacuum chamber. The anneal process was started under vacuum of $1.0 \times 10^{-5}$ Torr. The samples were then allowed to cool in vacuum.

Results: The resulting films were analysed using Auger electron spectroscopy (AES) depth profiles carried out on a VG310F scanning Auger microprobe. A full spectrum (at a constant retard ratio of 4 and a beam voltage of $10 \mathrm{kV}$ ) was collected after each sputter etch cycle and the depth profiles against argon ion sputter time were constructed from the measured peak areas using the library sensitivity factors in the Avantage software package. Depth profiles show that the sputtered nickel films annealed using conditions (i), (ii), and (iii) did not react uniformly with silicon (Fig. 1). The AES depth profile of sputtered nickel films vacuum annealed at $600^{\circ} \mathrm{C}$ for $90 \mathrm{~min}$ (not shown) shows more complete reaction with silicon, giving NiSi with a composition of $48 \%$ nickel to $52 \%$ silicon.

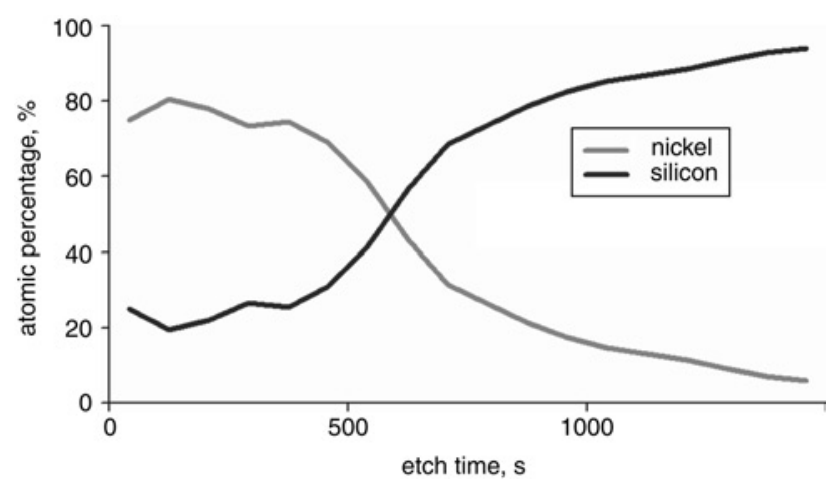

Fig. 1 Auger electron spectroscopy depth profile for sputtered nickel on silicon vacuum annealed at $250^{\circ} \mathrm{C}$ for $1 \mathrm{~h}$, followed by $350^{\circ} \mathrm{C}$ for $3 \mathrm{~h}$

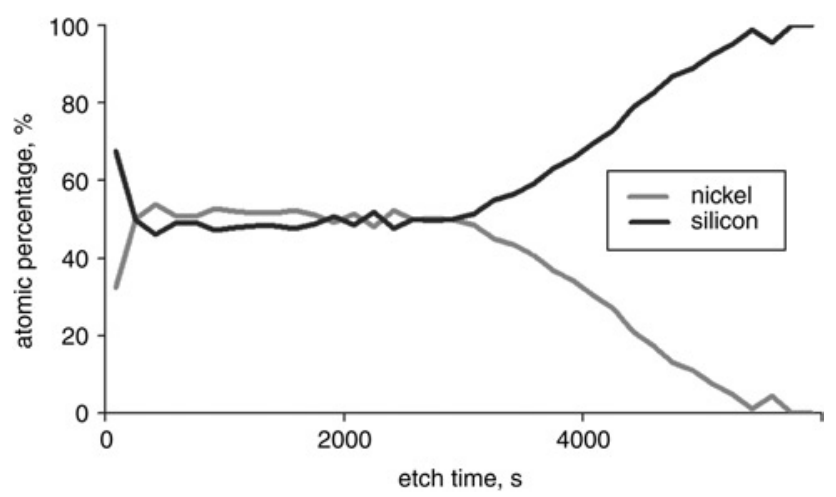

Fig. 2 Auger electron spectroscopy depth profile for evaporated nickel on silicon vacuum annealed at $350^{\circ} \mathrm{C}$ for $30 \mathrm{~min}$

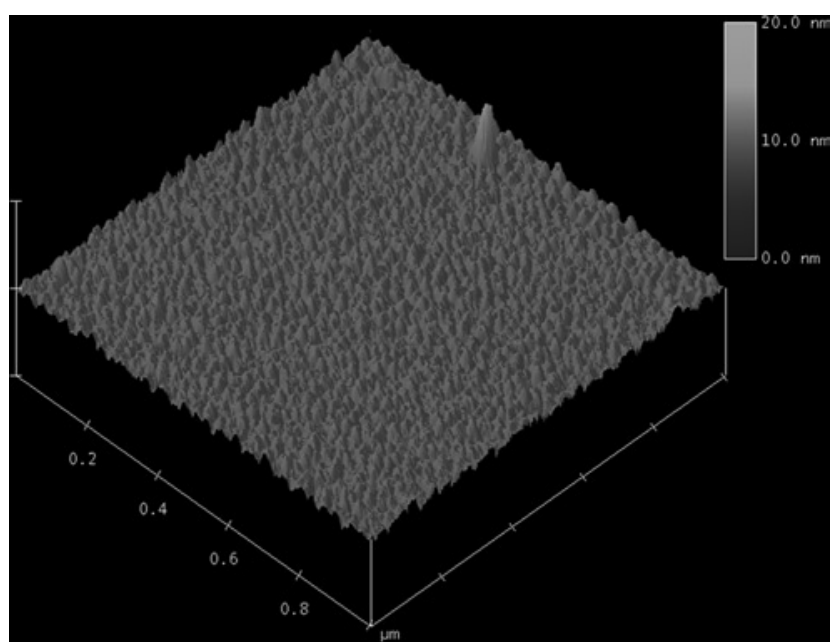

Fig. 3 Atomic force microscope surface scans over $1 \times 1 \mu$ area of nickel silicide formed from evaporated nickel on silicon by vacuum annealing at $350^{\circ} \mathrm{C}$ for $30 \mathrm{~min}$

Evaporated nickel films reacted using the same conditions formed NiSi films, with the composition of the silicide being $49-50 \%$ nickel and 51-50\% silicon. Evaporated nickel films were also vacuum annealed at $350^{\circ} \mathrm{C}$ for different time periods of $30 \mathrm{~min}$ and $1 \mathrm{~h}$. Depth profiles of these films (formed using $50 \mathrm{~nm}$ evaporated nickel) showed them to be NiSi (with nickel and silicon ratios of almost 50:50). Fig. 2 depicts the depth profile obtained for a NiSi film which was formed after $30 \mathrm{~min}$ of vacuum annealing at $350^{\circ} \mathrm{C}$. The depth profiles of NiSi films formed with evaporated nickel using conditions (i), (ii), and (iii) were similar to Fig. 2.

Atomic force microscope (Digital Instruments Dimension 3100) surface scans of $\mathrm{NiSi}$ thin films formed from evaporated nickel $\left(350^{\circ} \mathrm{C}\right.$ for $\left.30 \mathrm{~min}\right)$ showed that their average surface roughness was

\section{ELECTRONICS LETTERS 12th April 2007 Vol. 43 No. 8}


found to be $0.67 \mathrm{~nm}$ (Fig. 3), compared to $9.77 \mathrm{~nm}$ for the silicide formed at $600^{\circ} \mathrm{C}$ from sputtered nickel.

Discussion: Nickel silicide films formed by vacuum annealing of electron-beam evaporated nickel were found to be $\mathrm{NiSi}$, with the composition being very close to $50 \%$ nickel and $50 \%$ silicon. For evaporated nickel films, all reported temperature and time conditions resulted in films of required composition. No traces of oxygen were found in any of the films. The measured step-height of nickel silicide film above the surface of silicon, the total amount of nickel silicide formed, and the measured thin film resistivity values of $14 \mu \Omega$-cm correspond very well to the values reported in the published literature [3].

Compared to evaporated nickel films, it was found that more thermal effort was required to form NiSi using sputtered nickel films. Only sputtered nickel films which were annealed at a high temperature of $600^{\circ} \mathrm{C}$ appeared to have completely reacted. This could be attributed to variations in the diffusivity of metals in silicon, based on the metal thin film deposition technique [4].

Conclusion: Conditions for the formation of nickel silicide thin films, for use in microsystem fabrication, have been discussed. Nickel silicide films formed by vacuum annealing of sputtered and evaporated nickel films have been compared using Auger electron spectroscopy depth profiles. Nickel silicide of NiSi composition was formed using evaporated nickel using several annealing temperatures and time periods. Higher thermal energy was required to form NiSi using sputtered nickel films, which did not react uniformly with silicon at lower temperature conditions.
(C) The Institution of Engineering and Technology 2007

21 January 2007

Electronics Letters online no: 20070203

doi: 10.1049/el:20070203

M. Bhaskaran, S. Sriram and A.S. Holland (Microelectronics and Materials Technology Centre, School of Electrical and Computer Engineering, RMIT University, GPO Box 2476V, Melbourne, Victoria 3001, Australia)

E-mail: madhu.bhaskaran@gmail.com

J. du Plessis (School of Applied Sciences, RMIT University, GPO Box 2476V, Melbourne, Victoria 3001, Australia)

\section{References}

1 Qin, M., Poon, M.C., and Yuen, C.Y.: 'A study of nickel silicide film as a mechanical material', Sens. Actuators A, 2000, 87, p. 90

2 Clevenger, L.A., and Mann, R.W.: 'Schottky barrier heights of TM silicides on Si and GaAs' in Maex, K., and Van Rossum, M. (Eds): 'Properties of metal silicides' (INSPEC, London, 1995), p. 64

3 Plummer, J.D., Deal, M.D., and Griffin, P.B.: 'Silicon VLSI technology: fundamentals, practice and modeling' (Prentice-Hall, Inc, New Jersey, 2000), p. 700

4 Thomä, A.: J. Phys., Condens. Matter, 1990, 2, p. 3167 